\title{
NEW ROUTE TO MESOPOROUS SILICA VIA A SILSESQUIOXANE PRECURSOR
}

\author{
"ROBERT E. PRZEKOP*, BOGNA SZTORCH*, MICHAŁ ZIELIŃSKI**, MARIUSZ PIETROWSKI**, \\ PIOTRMARCINIAK*,AGNIESZKAMARTYLA***,MONIKAOSINSKA-BRONIARZ***,BOGDANMARCINIEC*,** \\ *Adam Mickiewicz University in Poznań, Centre for Advanced Technologies, Umultowska 89c, 61-614 Poznań, Poland \\ **Adam Mickiewicz University in Poznań, Faculty of Chemistry, Umultowska 89b, 61-614 Poznań, Poland \\ ***Institute of Non-Ferrous Metals, Division in Poznan, Central Laboratory of Batteries and Cells, \\ Forteczna 12, 61-362 Poznań, Poland \\ ${ }^{\#}$ E-mail: r.przekop@gmail.com
}

Submitted June 20, 2018; accepted August 13, 2018

Keywords: Octaanion, Porous materials, Textural promoters, Silsesquioxane

The effect of the addition of octakis(tetramethylammonium)-t8-silsesquioxane (octaanion) on the modification of the porous structure of the silica gel obtained by the sol-gel method catalysed by acetic acid was studied. The obtained silica gel was characterised by the low-temperature nitrogen adsorption/desorption method (BET), powder diffraction (XRD), thermogravimetry (TG) and microscopic observations (TEM). The octaanion was found to act as a textural promoter, as evidenced by almost a $25 \%$ increase in the surface area of the obtained silica. As a result of the stabilisation in the porous structure of the silica gel, the tetramethylammonium groups of the octaanion show higher thermal stability than the groups present in the octaanion structure or those introduced in the form of tetramethylammonium hydroxide. Tetramethylammonium ions were proved to show increased thermal resistance, which is related to the porous properties of the $\mathrm{SiO}_{2}$ matrix.

\section{INTRODUCTION}

The quaternary ammonium ion shows strong structure-determining properties, therefore it can be applied for the dissolution of silica by the generation of cage structures, $\mathrm{Q}_{\mathrm{x}}$, where $\mathrm{x}=6,8,10$ [1]. The addition of quaternary ammonium hydroxides to a reaction mixture increases its $\mathrm{pH}$. The use of hydroxides of different alkyl chains can lead to obtaining materials of different degrees of organisation and ordering [2]. One of the methods for the generation of polyanionic cage structures $Q_{x}$ is the dissolution of silica characterised by a high surface area in the solutions of tetraalkylammonium hydroxides of concentrations higher than 0.2 M [1]. On the other hand, tetraalkylammonium hydroxides are used in the synthesis of ordered porous materials, mainly zeolites [3] and mesoporous materials [4]. The process of selective extraction of the $\mathrm{Si}-\mathrm{O}-\mathrm{Si}$ lattice in the silica is known as desilication or basic leaching and has been widely used for obtaining hierarchic materials, e.g., zeolites [5-9]. The leaching agent, which is quaternary ammonium hydroxide, has a specific effect on the kinetics of the process. The rate of silica dissolution in tetrabutylammonium or tetrapropylammonium hydroxide is much lower than in $\mathrm{NaOH}$, which means that the process of dilution can be better controlled in the former two hydroxides. The size of the alkylammonium cation and strength of the hydroxide determine the porosity of the obtained material [4]. The final stage of the material's processing is the decomposition of the alkylammonium cation by thermal treatment in oxidising conditions, leading to the formation of the protonated form of the porous material which can subsequently be subjected to an ionic exchange [10].

Besides the kinetic effect, tetraalkylammonium cations also have an impact on the preferred stabilisation of the symmetric cage structures in the solution. If the solution concentration is $\left[\mathrm{OH}^{-}\right]:[\mathrm{Si}] \geq 1: 1$, the preferred formation of the silicate anion $\mathrm{Si}_{8} \mathrm{O}_{20}{ }^{8-}$ stabilised by 8 tetramethylammonium $\left(\mathrm{TMA}^{+}\right)$cations is observed. The cations of ammonium hydroxides make a stabilising hydrophobic shell protecting the anion core against hydrolysis [11]. The study reported in this paper was undertaken to establish the impact of the introduction of an octaanion into a stable silica gel solution (obtained by the sol-gel method) on the final structure and texture of the obtained adsorbing material. For the sake of comparison, the analogous adsorbing material was synthesised with the equivalent amount of tetramethylammonium hydroxide introduced into the same amount of silica gel. 


\section{EXPERIMENTAL}

\section{Synthesis of $\mathrm{SiO}_{2}$}

Modified silica systems were synthesised by the aqueous sol-gel method. The synthesis was based on our previous experience with similar system preparations [12-14].

A glass reactor of 11 in capacity, equipped with a reflux, dropping funnel, mechanical stirrer and heating mantle, was charged with $500 \mathrm{ml} \mathrm{H}_{2} \mathrm{O}(27.7 \mathrm{~mol})$ of water, $35 \mathrm{ml}$ acetic acid $(0.333 \mathrm{~mol})$ and $100 \mathrm{ml}$ tetraethoxysilane (TEOS $-0.48 \mathrm{~mol} \mathrm{Si}$ ). The mixture was heated at $80^{\circ} \mathrm{C}$ for $24 \mathrm{~h}$. The obtained iridescent gel was mixed for the next $24 \mathrm{~h}$ at room temperature. As a result of hydrolysis and condensation, an $\mathrm{SiO}_{2}$ gel was obtained and evaporated under reduced pressure $(p=500 \mathrm{hPa})$ at $90^{\circ} \mathrm{C}$. The silica obtained in this way was labelled as $\mathrm{SiO}_{2}$.

\section{Synthesis of octakis(tetramethylammonium)- -t8-silsesquioxane (octaanion)}

A glass reactor of 11 in capacity, equipped with a reflux, dropping funnel, mechanical stirrer, was charged with $177.6 \mathrm{ml}, 25 \% \mathrm{w} / \mathrm{w}$ water solution of tetramethylammonium hydroxide ( $0.48 \mathrm{~mol}$, TMAH), $90.8 \mathrm{ml}$ $(2.27 \mathrm{~mol})$ of methanol and $68.4 \mathrm{ml}(3.8 \mathrm{~mol})$ of water. The mixture was cooled to $0^{\circ} \mathrm{C}$ and then $100 \mathrm{ml}$ of tetraethoxysilane (TEOS $-0.48 \mathrm{~mol} \mathrm{Si}$ ) was added dropwise upon vigorous stirring. The solution was stirred for $24 \mathrm{~h}$ at room temperature. The reaction gave a solution of the octaanion. The solvent was evaporated under reduced pressure $(\mathrm{p}=500 \mathrm{hPa})$ at $90^{\circ} \mathrm{C}$. The octakis(tetramethylammonium)-T8-silsesquioxane sample was labelled as OCTA.

\section{Synthesis of $\mathrm{SiO}_{2}$ with the octaanion addition}

Portions of $7.14 \mathrm{~g}$ of octaanion $\left(\mathrm{SiO}_{2}=0.033 \mathrm{~mol}\right.$, the sample denoted as Si-OCTA1) or $20.74 \mathrm{~g}$ of octaanion $\left(\mathrm{SiO}_{2}=0.098 \mathrm{~mol}\right.$, the sample denoted as Si-OCTA2) were added to the $\mathrm{SiO}_{2}$ gel $(0.48 \mathrm{~mol} \mathrm{Si})$, obtained according to the procedure described in chapter "Synthesis of $\mathrm{SiO}_{2}$ ". (prior to evaporation) at room temperature. Further steps of the preparation method: the evaporation and drying were the same as that for $\mathrm{SiO}_{2}$.

\section{Synthesis of $\mathrm{SiO}_{2}$ with the TMAH addition}

Portions of $177.6 \mathrm{ml}$ of tetramethylammonium hydroxide (Aldrich, $25 \% \mathrm{w} / \mathrm{w}$ methanol solution) (0.48 mol TMAH) the sample labelled as Si-TMAH, or $36.27 \mathrm{ml}$ of tetramethylammonium hydroxide (Aldrich, $25 \% \mathrm{w} / \mathrm{w}$ methanol solution) (0.098 mol TMAH), the sample labelled as $\mathrm{Si}$-TMAH2, were added to $\mathrm{SiO}_{2}$
$(0.48 \mathrm{~mol} \mathrm{Si})$ obtained according to the procedure described in in chapter "Synthesis of $\mathrm{SiO}_{2}$ ". (prior to evaporation) at room temperature. In the latter Si-TMAH2 sample, the amount of TMAH added is equimolar with the OCTA introduced to the synthesis of Si-OCTA2. Further steps of the procedure: the evaporation and drying were the same as that for $\mathrm{SiO}_{2}$.

All obtained sample labelling and molar compositions are presented in Table 1.

Table 1. Sample labelling and molar composition of the silicon obtained by the acetate method to the silicon contained in the tetramethylammonium hydroxide.

\begin{tabular}{lccc}
\hline Sample code & $\begin{array}{c}\mathrm{Si}_{\text {TEOS }} \\
\left(\mathrm{mol}_{0}\right)\end{array}$ & $\begin{array}{c}\mathrm{Si}_{\text {TMAH }} \\
(\mathrm{mol.} \%)\end{array}$ & $\mathrm{Si}_{\text {OCTA }} / \mathrm{Si}_{\text {gel }}$ \\
\hline OCTA & - & 100 & - \\
$\mathrm{SiO}_{2}$ & 100 & - & - \\
Si-OKTA1 & 93.6 & 6.4 & 0.0688 \\
Si-OKTA2 & 83.1 & 16.9 & 0.2042 \\
Si-TMAH2 & 83.1 & 16.9 & 0.2042 \\
Si-TMAH & - & 100 & - \\
\hline
\end{tabular}

\section{Thermal treatment}

The samples were dried at $90^{\circ} \mathrm{C}$ and then calcined in a tube furnace in an air atmosphere, at $500^{\circ} \mathrm{C}$ for 6 hours.

\section{Characterisation of the porous structure}

Prior to the determination of the porous structure, the samples were calcined at $500^{\circ} \mathrm{C}$ (see Thermal treatment). The porous structure was determined by low temperature $\left(-196^{\circ} \mathrm{C}\right)$ nitrogen adsorption/desorption measurements carried out with an Accelerated Surface Area and Porosimetry System model 2010 V2.00 D made by Micromeritics, using $200-300 \mathrm{mg}$ of the samples with a grain size fraction between $0.1-0.2 \mathrm{~mm}$. Prior to the nitrogen adsorption, all the samples were outgassed at $400^{\circ} \mathrm{C}$ at $0.4 \mathrm{~Pa}$ till a constant weight. Both the adsorptive and desorptive branches of the isotherm were recorded in the range of $\mathrm{p} / \mathrm{p}_{0} 0-1$.

\section{XRD analysis}

The X-ray powder diffraction patterns of the samples (after thermal treatment $-500^{\circ} \mathrm{C}$ in an air atmosphere for 6 hours) were taken on a Philips PW1050 diffractometer, with Ni filtered $\mathrm{CuK} \alpha$ radiation. The reflections position, half bandwidth as well as the intensity were calculated by the APD Philips programme.

\section{Thermal analysis}

The thermal transformation of the gel samples was carried out on a TA Q50 (TA) under the same conditions. A ca. $20 \mathrm{mg}$ sample was placed in a platinum dish 
and heated at a rate of $20^{\circ} \mathrm{C} \cdot \mathrm{min}^{-1}$ up to $800^{\circ} \mathrm{C}$. For all the experiments, we used the fraction of grain size below $0.1 \mathrm{~mm}$. The TG traces were recorded in an air atmosphere. For the thermal analysis, we used vacuum dried samples $\left(90^{\circ} \mathrm{C}\right)$ with an excess of encapsulated solvents removed from the gel by evaporative drying.

\section{TEM analysis}

The gel structures were characterised by transmission electron microscopy (JEOL 200 CX Jeol).

\section{RESULTS AND DISCUSSION}

In our study, octaanion was used as a modifier of the structure of the $\mathrm{SiO}_{2}$ gel obtained by the standard sol-gel method [12-14]. The octaanion can react with the acetic acid present in the $\mathrm{SiO}_{2}$ gel:

$$
\begin{aligned}
& {\left[\mathrm{Si}_{8} \mathrm{O}_{20} \cdot 8 \mathrm{TMA}\right]+\mathrm{CH}_{3} \mathrm{COO}^{-} \rightarrow} \\
& \rightarrow\left[\mathrm{Si}_{8} \mathrm{O}_{19} \cdot 7 \mathrm{TMA}\right]-\mathrm{O}^{-}+\mathrm{CH}_{3} \mathrm{COOTMA}
\end{aligned}
$$

the ion formed $\left[\mathrm{Si}_{8} \mathrm{O}_{19} \cdot 7 \mathrm{TMA}\right]-\mathrm{O}^{-}$undergoes a condensation reaction with the silanol groups present in the $\mathrm{SiO}_{2}$ gel structure:

$$
\begin{aligned}
& {\left[\mathrm{Si}_{8} \mathrm{O}_{19} \cdot 7 \mathrm{TMA}\right]-\mathrm{O}^{-}+\mathrm{HO}-\mathrm{Si} \equiv \rightarrow} \\
& \rightarrow\left[\mathrm{Si}_{8} \mathrm{O}_{19} \cdot 7 \mathrm{TMA}\right]-\mathrm{O}-\mathrm{Si} \equiv+\mathrm{OH}^{-}
\end{aligned}
$$

and further reactions with acetic acid:

$$
\begin{aligned}
& {\left[\mathrm{Si}_{8} \mathrm{O}_{19} \cdot 7 \mathrm{TMA}\right]-\mathrm{O}-\mathrm{Si} \equiv+\mathrm{CH}_{3} \mathrm{COO}^{-} \rightarrow} \\
& \rightarrow\left\{\left[\mathrm{Si}_{8} \mathrm{O}_{20} \cdot 6 \mathrm{TMA}\right]-\mathrm{O}-\mathrm{Si} \equiv\right\}^{-}+\mathrm{CH}_{3} \mathrm{COOTMA}
\end{aligned}
$$

The gel samples dried at $90{ }^{\circ} \mathrm{C}$ were subjected to a thermogravimetric study (Figure 1). The mass loss curve recorded for the initial silica gel (curve B) showed a maximum corresponding to the removal of water at $103^{\circ} \mathrm{C}$ and an inflection point in the range $\sim 160-170^{\circ} \mathrm{C}$, assigned to the removal of the residues of acetic acid.

For the OCTA sample, three mass loss maxima

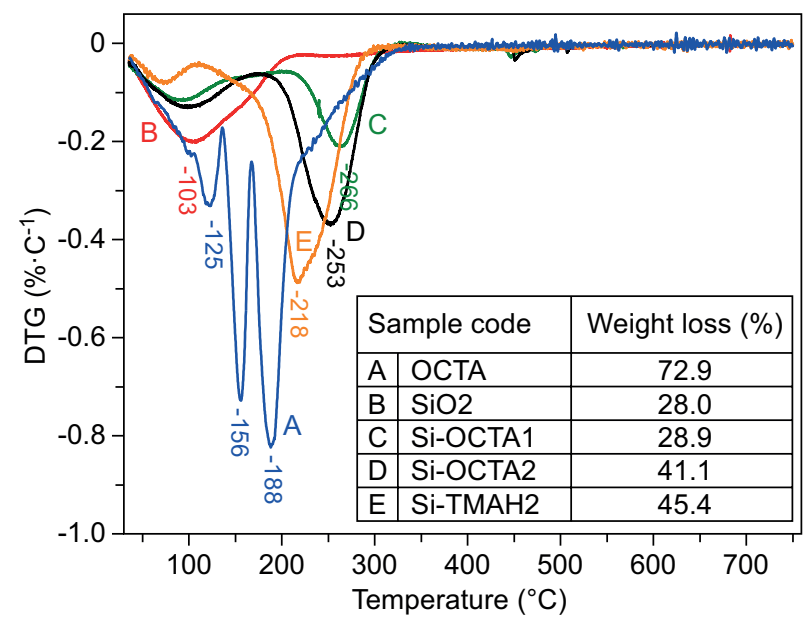

Figure 1. The thermogravimetric curves and weight losses of the silica gel systems in an air atmosphere. were recorded (Curve A). The decomposition of the pure octaanion runs as follows:

$$
\text { [Octaanion } \left.\cdot \mathrm{H}_{2} \mathrm{O}\right] \rightarrow[\text { Octaanion }] \rightarrow \mathrm{SiO}_{2}
$$

The theoretical mass loss related to the removal of all TMA+ groups should be $57.8 \%$. It corresponds to the sum of two separate mass loss events at $156^{\circ} \mathrm{C}$ and $188^{\circ} \mathrm{C}$, which is $56.1 \%$. The former one corresponds to the removal of water and amounts to $16.8 \%$ corresponding to 16.53 of $\mathrm{H}_{2} \mathrm{O}$ molecules per one molecule of the octaanion.

The TG curves recorded for the $\mathrm{SiO}_{2}$ samples modified with the octaanion (Si-OCTA1 and Si-OCTA2) show two peaks, assigned to the removal of water at $103^{\circ} \mathrm{C}$ and to the removal of $\mathrm{TMA}^{+}$ions above $200^{\circ} \mathrm{C}$. A shift of the $\mathrm{TMA}^{+}$decomposition temperature towards higher values for the mixed systems with respect to that of pure OCTA is related to the ions' stabilisation in the closed structures and their greater resistance to temperature. This effect has also been observed for $\mathrm{TMA}^{+}$ions confined in a zeolite cage [15]. The confined ions are more resistant to decomposition. In the, the situation is the reverse: $\mathrm{TMA}^{+}$ions are directed outwards from the structure, so their thermal resistance is lower, as confirmed by the DTG results. The effect of stabilisation weakens with the increasing content of $\mathrm{TMA}^{+}$. After the addition of a considerable amount of the octaanion, the high-temperature peak is shifted towards the lower temperatures of $266^{\circ} \mathrm{C}$ for Si-OCTA 1 and $253^{\circ} \mathrm{C}$ for SiOCTA2. It should be noted that above $300^{\circ} \mathrm{C}$ no mass loss was observed, irrespective of using octaanion or TMAH as a modifier. The thermal stabilisation of the $\mathrm{TMA}^{+}$ions is greater than that of the pure octaanion and smaller than that of the zeolites. Moreover, the stability of the $\mathrm{TMA}^{+}$ions is higher for the systems whose precursor is an octaanion, so these systems should have a structure closer to that of zeolites, however the XRD results indicated no ordered structure (as presented and discussed below).

Silica gels modified with the octaanion and TMAH were subjected to calcination at $500^{\circ} \mathrm{C}$ in order to get $\mathrm{SiO}_{2}$. As follows from low-temperature nitrogen adsorption/desorption studies, the initial $\mathrm{SiO}_{2}$ has a microporous character (Figure 2a) and a surface area of $319 \mathrm{~m}^{2} \cdot \mathrm{g}^{-1}$, Table 2 . The use of an octaanion as the agent promoting texture development leads to an increase in the surface area to 444 or $377 \mathrm{~m}^{2} \cdot \mathrm{g}^{-1}$ depending on the amount of the promoter added (Table 2). For the sake of comparison, the texture of the octaanion subjected to calcination $500^{\circ} \mathrm{C}$ was characterised. The material obtained had a low surface area of $27 \mathrm{~m}^{2} \cdot \mathrm{g}^{-1}$ and a pore diameter of about $10 \mathrm{~nm}$, which means that it is mesoporous. The addition of greater amounts of OCTA to the $\mathrm{SiO}_{2}$ gel causes a decrease in the surface area, which was observed for the Si-OCTA1 and Si-OCTA2 samples.

Textural changes in the samples after the addition of 


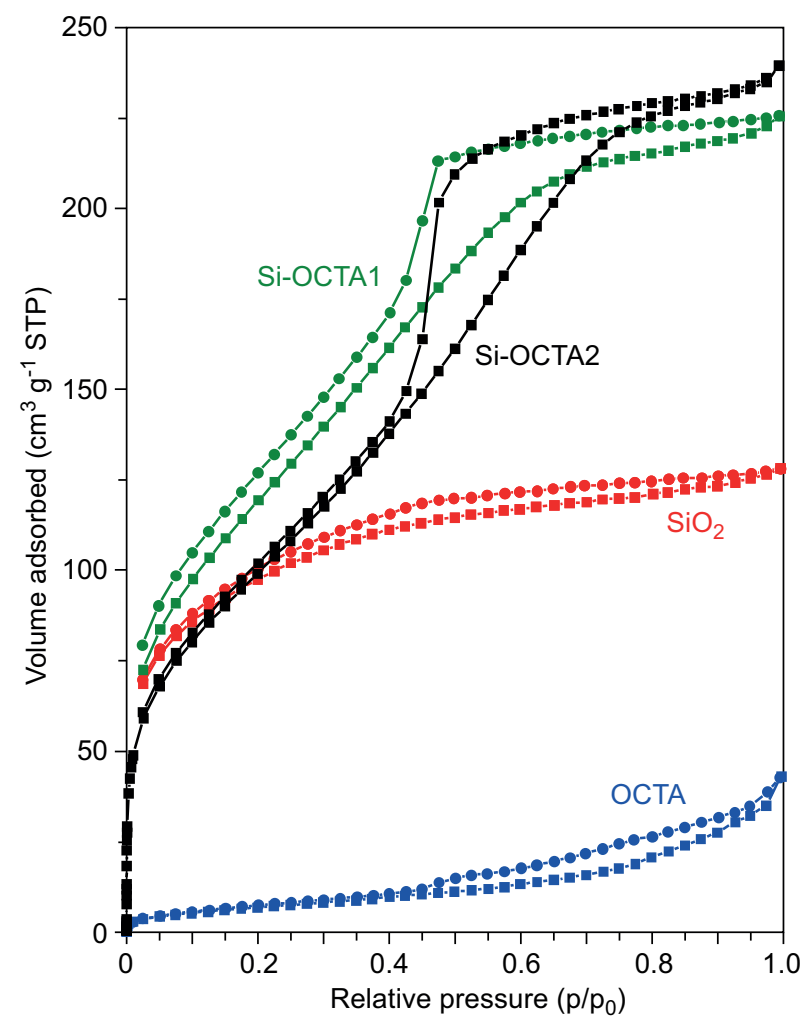

a) OCTA

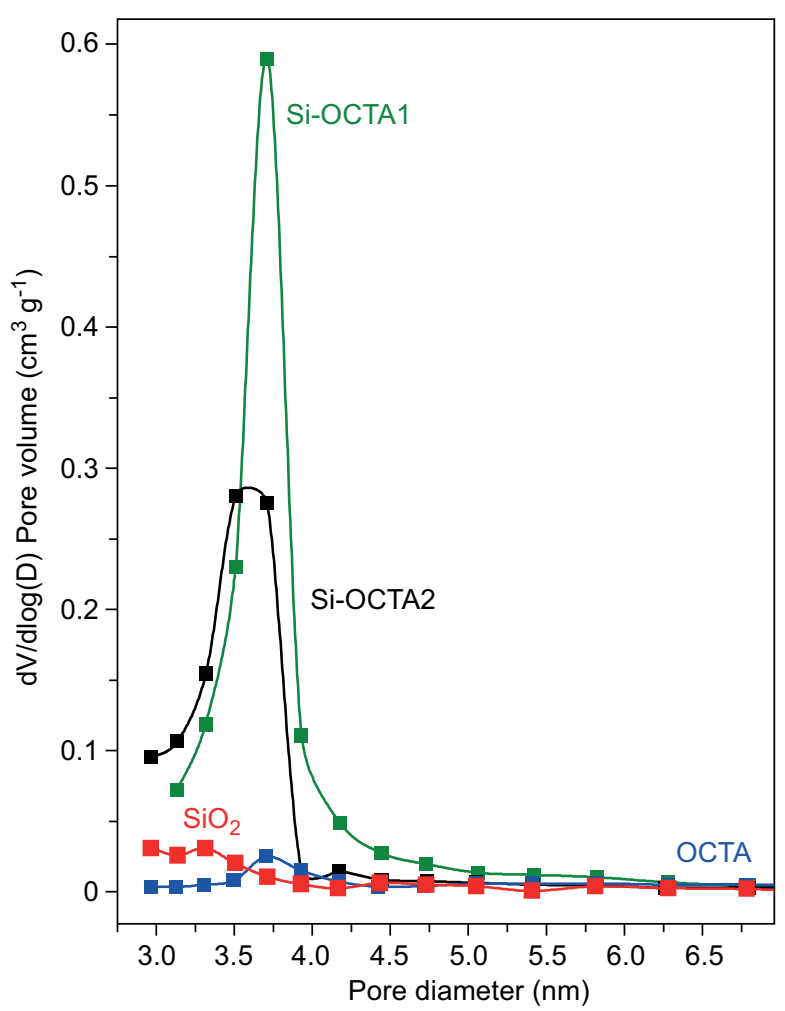

b) OCTA
OCTA are particularly well pronounced in the character of the low-temperature nitrogen adsorption/desorption, Figure 2a. The isotherm obtained for the initial silica $\left(\mathrm{SiO}_{2}\right)$ is of type $\mathrm{I}(\mathrm{b})$ according to the recent IUPAC classification [16] and is typical of materials having a pore size distribution over a broader range including wider micropores and possibly narrow mesopores $(<\sim 2.5 \mathrm{~nm})$. Poorly marked, but a visible hysteresis loop, occurs in practically the whole range of partial pressures $\mathrm{p} / \mathrm{p}_{0}$ which confirms the presence of wide micropores and capillary condensation taking place in the very narrow mesopores. The pore size distribution covers the range from 3 to $5 \mathrm{~nm}$, with no distinct maximum (Figure $2 \mathrm{~b}$ ).

The use of octaanion as a texture promoting agent in the process of the silica gel synthesis provokes significant changes, not only in the surface area, but also in the pore structure, as manifested by the shape of the isotherm typical of Type IV(a) and the shape of the hysteresis loop described as H2(a), in particular, for the sample with a higher content of octaanion $\left(\mathrm{Si}_{\mathrm{TMAH}}=16.9 \%\right)-\mathrm{Si}$-OCTA2. The H2(a) loop is typical of mesoporous materials with a pore system for which network effects are important. The very steep desorption branch, which is a characteristic feature of H2(a) loops, can be attributed either to pore-blocking/percolation in a narrow range of pore necks or to cavitation-induced evaporation. The hysteresis loop recorded for Si-OCTA1

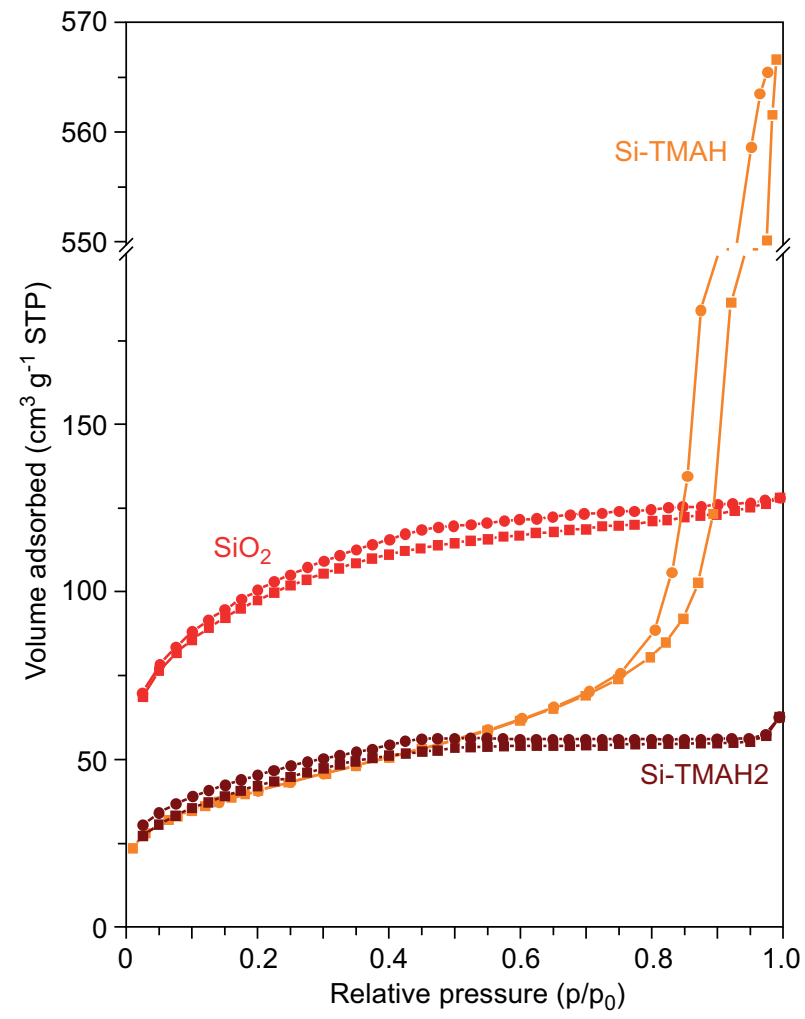

c) TMAH

Figure 2. Low temperature nitrogen adsorption isotherms and pore size distribution of $\mathrm{SiO} 2$ modified by the octaanion (OCTA) (a and $\mathrm{b}$ ) and tetramethylammonium hydroxide (TMAH) 
$\left(\mathrm{Si}_{\mathrm{OCTA}} / \mathrm{Si}_{\text {gel }}=0.0688\right)$ can also be classified as $\mathrm{H} 2(\mathrm{a})$, however, the not fully-closed hysteresis loop occurring in the $\mathrm{p} / \mathrm{p}_{0}$ range from 0 to 0.5 is the evidence of the presence of wide micropores of average size of $3.1 \mathrm{~nm}$, which means that the materials borders on micro- and mesoporous ones, Figure $2 b$ and Table 2. Samples SiOCTA1 and Si-OCTA2 are characterised by very narrow pore size distribution, the majority of them have diameters between 3 and $4.5 \mathrm{~nm}$, the mean pore diameter is 3.1 and $3.9 \mathrm{~nm}$, respectively.

For $\mathrm{SiO}_{2}$, the type of structural promoter added in

Table 2. Textural characteristics of the samples after calcination in air at $500^{\circ} \mathrm{C}$ for $6 \mathrm{~h}$.

\begin{tabular}{lcc}
\hline Sample code & $\begin{array}{c}\text { BET surface } \\
\text { area }\left(\mathrm{m}^{2} \cdot \mathrm{g}^{-1}\right)\end{array}$ & $\begin{array}{c}\text { Average pore } \\
\text { diameter* }(\mathrm{nm})\end{array}$ \\
\hline OCTA & 27 & 9.9 \\
SiO2 & 319 & 2.5 \\
Si-OCTA1 & 444 & 3.1 \\
Si-OCTA2 & 377 & 3.9 \\
Si-TMAH2 & 147 & 2.6 \\
Si-TMAH & 144 & 23.2 \\
\hline
\end{tabular}

* calculated by BJH from the desorption branch of the isotherm

the process of the material synthesis had a great effect on the surface area and structure of the pores in the materials. The addition of OCTA resulted in an increase in the surface area, while the addition of TMAH caused its decrease, Table 2. The introduction of TMAH, in the amount equimolar to OCTA, directly into the gel of acidic character (Si-TMAH2) leads to a different porous structure, Figure 2c. The isotherm of nitrogen adsorption/

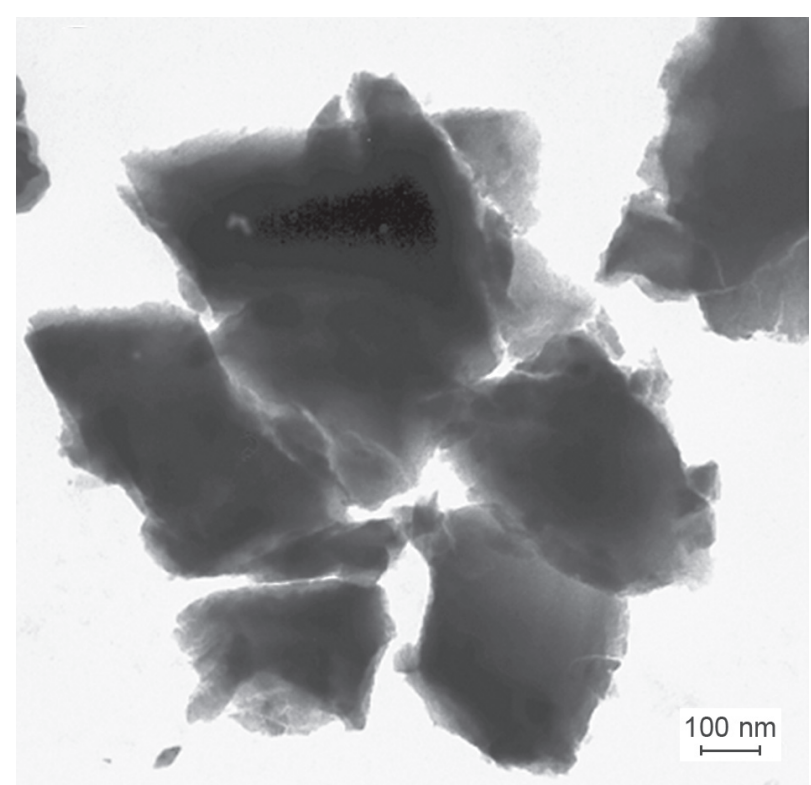

a) $\mathrm{SiO}_{2}$ gel sample desorption recorded for the system Si-TMAH2 does not show a hysteresis loop related to the capillary condensation in the mesopores. Apart from the reduction in the surface area from $319 \mathrm{~m}^{2} \cdot \mathrm{g}^{-1}$ for $\mathrm{SiO}_{2}$ to $147 \mathrm{~m}^{2} \cdot \mathrm{g}^{-1}$ for $\mathrm{Si}-\mathrm{TMAH} 2$, the average pore size remained practically the same and was $\sim 2.6 \mathrm{~nm}$. The isotherm recorded for Si-TMAH2 was of a I(b) type, which is characteristic of materials having a pore size distribution over a broader range including wider micropores and possibly narrow mesopores. The introduction of greater amounts of tetramethylammonium hydroxide (Si-TMAH) led to a typical mesoporous material whose nitrogen adsorption/ desorption isotherm had clear features of a Type IV(a) one [16]. The appearance of a Type H1 hysteresis loop indicates the presence of mesopores of a narrow diameter range and bottle pores with a neck size distribution similar to the width of the pore/cavity size distribution.

The microporous character of the initial silica has been confirmed by the transmission microscope images (TEM) - Figure 3a, clearly revealing a homogeneous structure of micropores. A small addition of octaanion to the silica gel ( $\mathrm{Si}$-OCTA1 $-\mathrm{Si}_{\mathrm{OCTA}} / \mathrm{Si}_{\text {gel }}=0.0688$ ) resulted in a considerable increase in the surface area $\left(444 \mathrm{~m}^{2} \cdot \mathrm{g}^{-1}\right.$ - Table 2) however, the morphology of this system remained very similar to that of standard silicas. No inhomogeneous areas were observed and the structure had features of an amorphous system (Figure 3b).

The TEM image of the octaanion (Figures 4a-d) is more complex, which indicates the diversity of its structure and the occurrence of ultramicroporous regions (Figure $4 \mathrm{a}, \mathrm{d}$ ) along with the areas of a cluster structure typical of silicas obtained with the use of basic catalysts (Figure 4b, c) [17, 18].

An increase in the amount of the octaanion intro-

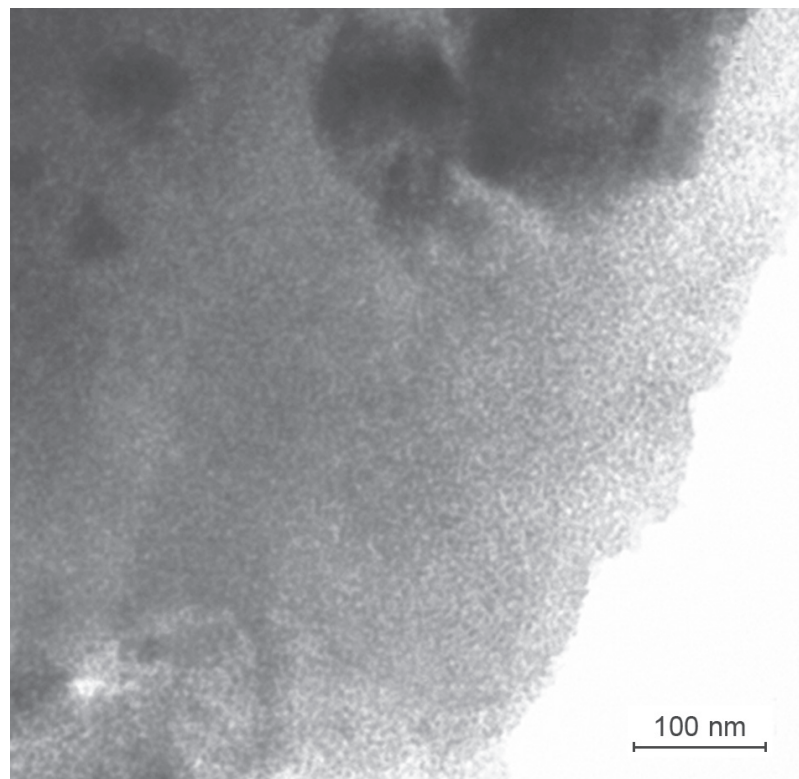

b) Si-OCTA1

Figure 3. TEM images: a) $\mathrm{SiO}_{2}$ gel sample, b) Si-OCTA1. (Continue on next page) 


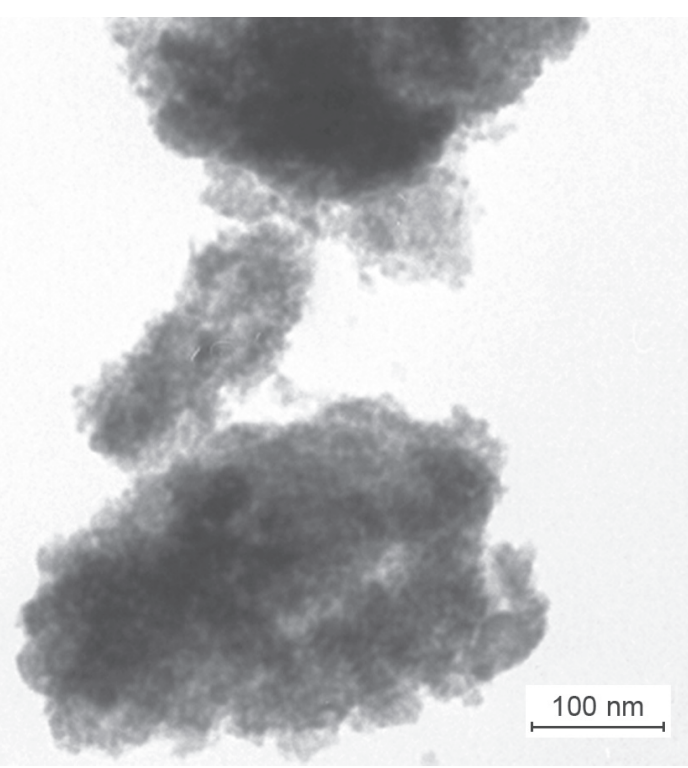

c) Si-OCTA2

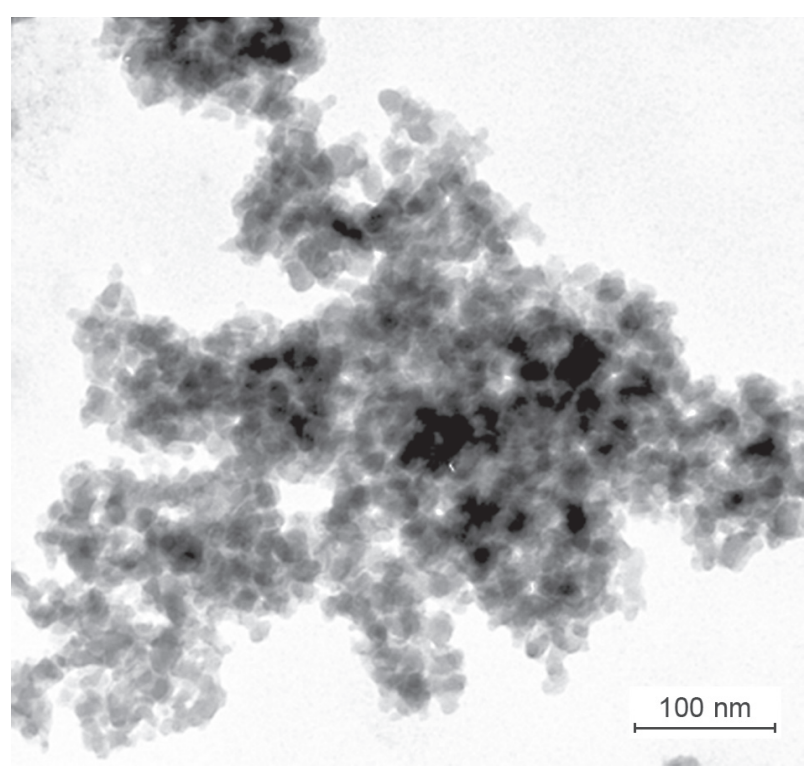

d) $\mathrm{Si}-\mathrm{TMAH}$

Figure 3. TEM images: c) Si-OCTA2, d) Si-TMAH.

duced into the basic gel obtained by the acidic method $\left(\mathrm{Si}_{\text {OCTA }} / \mathrm{Si}_{\text {gel }}=0.2042\right)$ results in the weakening of the effect of textural promotion, however, the surface area of this material is still much larger than that of the reference material $\left(377 \mathrm{~m}^{2} \cdot \mathrm{g}^{-1}\right.$ for Si-OCTA2). With the increasing content of the octaanion, the system begins to lose the features characteristic of the systems synthesised over acidic catalysts (Figure 3c), the appearance of distinct domains is observed which can become clusters characteristic of the systems synthesised over the basic catalysts on the increasing content of the hydroxide [19]. The microporous character of $\mathrm{Si}-\mathrm{TMAH} 2$ indicated by the results of nitrogen adsorption/desorption measurements was confirmed by the TEM images, Figure $3 \mathrm{~d}$.

The information on the structure of the materials obtained was supplemented with the XRD studies. In a small-angle range $(2 \Theta=0.5-5)$, no reflections assigned to the order mesoporous structure were detected. In the range $2 \Theta=5-100$, only the octaanion, not subjected to calcination, has a crystalline structure (Figure 5). The other systems show an amorphous structure indicated by a lack of reflections besides a broadened one, typical of silica in the range of $2 \Theta=21-26$.

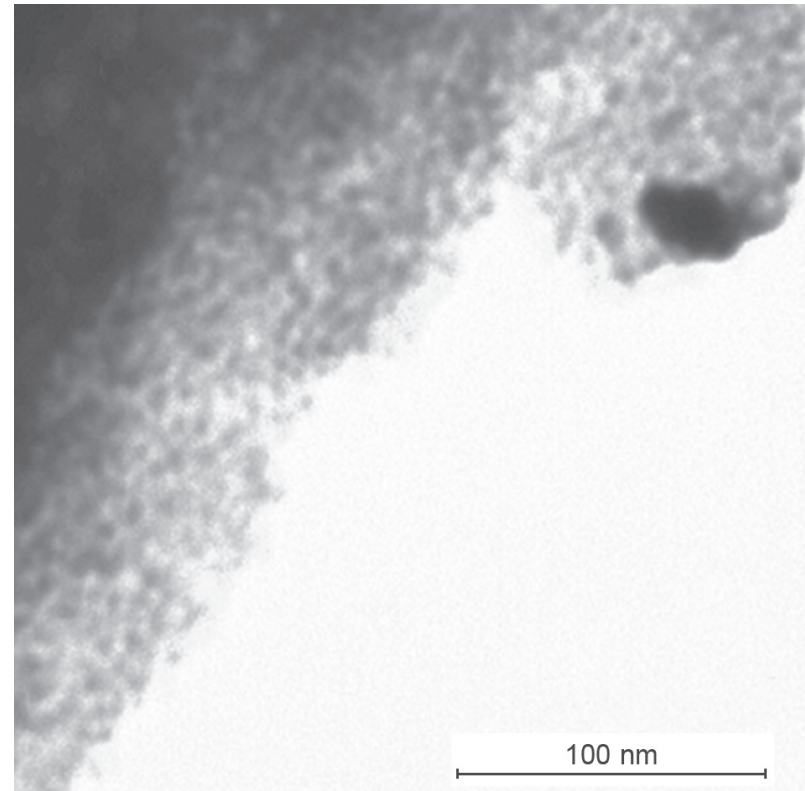

a) $\mathrm{SiO}_{2}$ gel sample

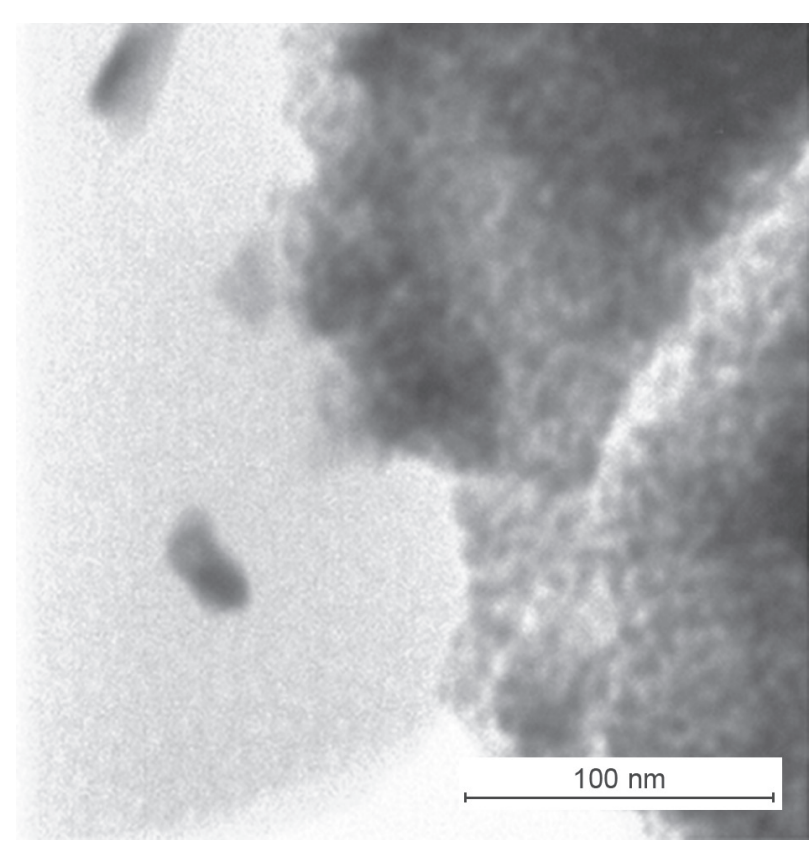

b) Si-OCTA1

Figure 4. TEM images of the calcinated octaanion: a) $\mathrm{SiO}_{2}$ gel sample, b) Si-OCTA1. (Continue on next page) 


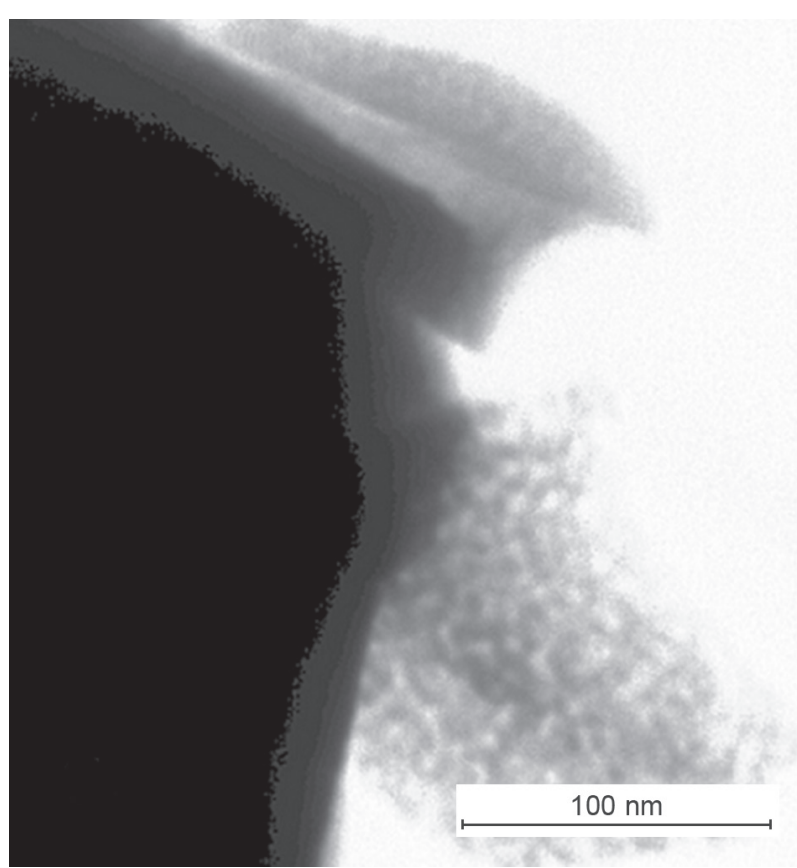

c) Si-OCTA2

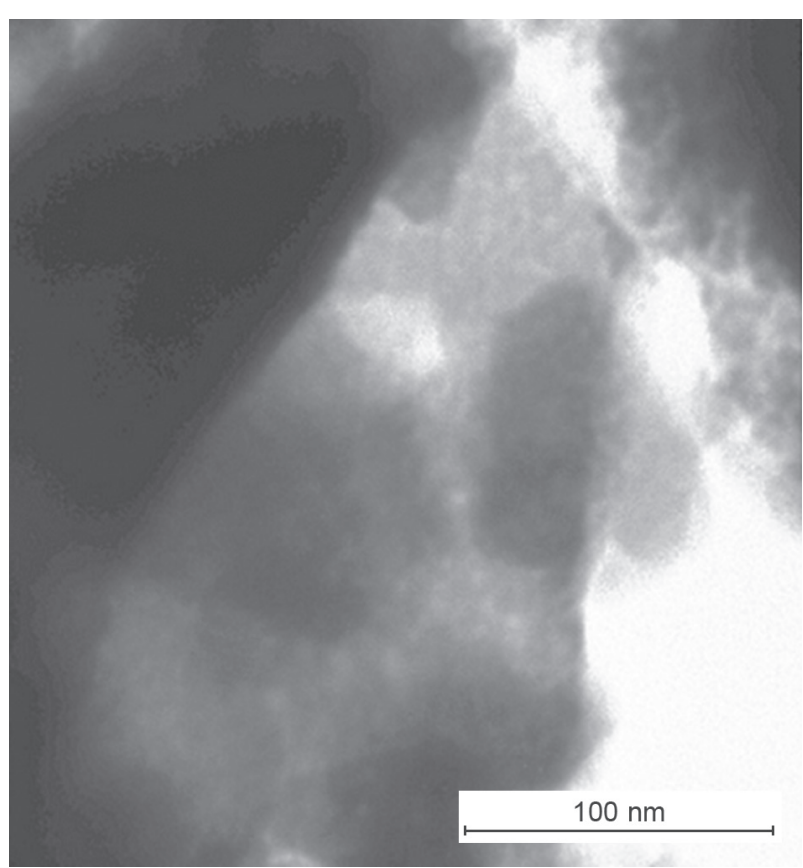

d) $\mathrm{Si}-\mathrm{TMAH}$

Figure 4. TEM images of the calcinated octaanion: c) Si-OCTA2, d) Si-TMAH.

\section{CONCLUSIONS}

- The addition of oktakis(tetramethylammonium)-T8-silisesquioxane (OCTA) to silica has a considerable effect on the development of its surface area, in contrast to a small effect of the direct addition of tetramethylammonium hydroxide (TMAH).

- The materials with the addition of OCTA show much greater thermal stability of the tetramethylammonium groups relative to that of the silica materials with TMAH.

- The thermal decomposition of OCTA leads to a material of small surface area containing a mixture of structures of diverse morphologies.

- The use of TMAH in the amount equilibrium to that of OCTA leads to a silica material of pore diameters close to $2.5 \mathrm{~nm}$, so similar to the unmodified silica, but of much smaller surface area.

- The addition of OCTA results in a change in the shape of the adsorption isotherm from a I(b) type characteristic of microporous materials, typical of a narrowpore silica, to a IVa type (with a hysteresis loop H2a), typical of mesoporous materials.

\section{Acknowledgement}

The study was financially supported from the National Centre for Research and Development in Poland (Grant No. PBS3/A1/16/2015) and statutory activity of Institute of Nonferrous Metals Division in Poznan Central Laboratory of Batteries and Cells.

Figure 5. The XRD patterns for the porous gel systems. 


\section{REFERENCES}

1. Laine R.M. (2005): Nanobuilding blocks based on the $\left[\mathrm{OSiO}_{1.5}\right]_{\mathrm{x}}(\mathrm{x}=56,8,10)$ octasilsesquioxanes. Journal of Materials Chemistry, 15, 3725-3744. doi: 10.1039/ B506815K

2. Lok B.M., Cannon T.R., Messina C.A. (1983): The role of organic molecules in molecular sieve synthesis. Zeolites, 3, 282-291. doi: 10.1016/0144-2449(83)90169-0

3. Cejka J., Corma A., Zones S. (2010). Zeolites and Catalysis Wiley-VCH, Weinheim. pp.2 - 882.

4. Abelló S., Bonilla A., Pérez-Ramírez J. (2009): Mesoporous ZSM-5 zeolite catalysts prepared by desilication with organic hydroxides and comparison with $\mathrm{NaOH}$ leaching. Applied Catalysis A: General, 364, 191-198. doi: 10.1016/j. apcata.2009.05.055

5. Ogura M., Shinomiya S., Tateno J., Nara Y., Nomura M., Kikuchi E., Matsukata M. (2001): Alkali-treatment technique - new method for modification of structural and acid-catalytic properties of ZSM-5 zeolites. Applied Catalysis A: General, 219, 33-43. doi: 10.1016/S0926860X(01)00645-7

6. Groen J.C., Peffer L.A.A., Moulijn J.A., Pérez-Ramírez J. (2004): Mesoporosity development in ZSM-5 zeolite upon optimized desilication conditions in alkaline medium. Colloids and Surfaces A: Physicochemical and Engineering Aspects, 241, 53-58. doi: 10.1016/j.colsurfa.2004.04.012

7. Groen J.C., Peffer L.A.A., Moulijn J.A., Pérez-Ramírez J. (2004): On the introduction of intracrystalline mesoporosity in zeolites upon desilication in alkaline medium. Microporous and Mesoporous Materials, 69, 29-34. doi:10.1016/j.micromeso.2004.01.002

8. Groen J.C., Peffer L.A.A., Moulijn J.A., Pérez-Ramírez J. (2005): Mechanism of hierarchical porosity development in MFI zeolites by desilication: The role of aluminium as a pore-directing agent. Chemistry: A European Journal, 11, 4983-4994. doi: 10.1002/chem.200500045

9. Groen J.C., Moulijn J.A., Pérez-Ramírez J. (2006): Desilication: on the controlled generation of mesoporosity in MFI zeolites. Journal of Materials Chemistry, 16, 2121-2131. doi: 10.1039/B517510K
10. Holm M.S., Hansen M.K., Christensen C.H. (2009): “OnePot" Ion-Exchange and Mesopore Formation During Desilication. European Journal of Inorganic Chemistry., 2009, 1194-1198 doi: 10.1002/ejic.200801194

11. Kinrade S.D., Knight Ch.T.G., Pole D.L., Syvitski R.T. (1998): Silicon-29 NMR Studies of Tetraalkylammonium Silicate Solutions. 1. Equilibria, ${ }^{29}$ Si Chemical Shifts, and ${ }^{29}$ Si Relaxation. Inorganic Chemistry, 37 (17), 4272-4277. doi: 10.1021/ic971629e

12. Martyła A., Olejnik B., Kirszensztejn P., Przekop R. (2011): Influence of the method of synthesis on hydrogen adsorption properties of mesoporous binary $\mathrm{B}_{2} \mathrm{O}_{3} / \mathrm{Al}_{2} \mathrm{O}_{3}$ gel systems. International Journal of Hydrogen Energy, 36, 8358-8364. doi: 10.1016/j.ijhydene.2011.04.091

13. Kirszensztejn P., Kawalko A., Tolinska A., Przekop R. (2011): Synthesis of $\mathrm{SiO}_{2}-\mathrm{SnO}_{2}$ gels in water free conditions. Journal of Porous Materials, 18 (2), 241-249. doi: 10.1007/s10934-010-9376-2

14. Pietras P., Przekop R., Maciejewski H. (2013): New approach to preparation of gelatine $/ \mathrm{SiO}_{2}$ hybrid systems by the sol-gel process. Ceramics Silikaty, 57(1), 58-65.

15. Kresnawahjuesa O., Olson D.H., Gorte R.J., Kühl G.H. (2002): Removal of tetramethylammonium cations from zeolites. Microporous and Mesoporous Materials, 51 (3), 175-188. doi: 10.1016/S1387-1811(01)00467-X

16. Thommes M., Kaneko K., Neimark A.V., Olivier J.P., Rodriguez-Reinoso F., Rouquérol J., Sing K.S.W. (2015): Physisorption of gases, with special reference to the evaluation of surface area and pore size distribution (IUPAC Technical Report). Pure and Applied Chemistry, 87, 1051-1069. doi: 10.1515/pac-2014-1117

17. Hench L.L., West J.K. (1990): The sol-gel process. Chemical Reviews, 90, 33-72.

18. Kurumada K., Nakabayashi H., Murataki T., Tanigali M. (1998): Structure and formation process of silica microparticles and monolithic gels prepared by the sol-gel method. Colloids and Surfaces A: Physicochemical and Engineering Aspects, 139, 163-170. doi: 10.1016/S09277757(98)00277-5

19. Lofgreena J.E., Ozin G.A. (2014): Controlling morphology and porosity to improve performance of molecularly imprinted sol-gel silica. Chemical Society Reviews, 43, 911-933. doi: 10.1039/C3CS60276A 